\title{
Consumer perception and sensory effect of oxidation in savory-flavored yogurt enriched with n-3 lipids
}

\author{
M. Rognlien, S. E. Duncan, ${ }^{1}$ S. F. O'Keefe, and W. N. Eigel \\ Department of Food Science and Technology, Virginia Tech, Blacksburg 24061
}

\begin{abstract}
The objective of this study was to determine the effects of different oils (butter, fish, and oxidized fish) on sensory characteristics of a savory [chile-lime (CL)] lowfat yogurt using descriptive (unstructured line scales, 5 attributes) and affective (hedonic) sensory testing methods. Yogurts were each manufactured at low [1.1-1.2\% total fat; $0.43 \%$ added oil (wt/wt)] or high [1.6\% total fat; $1 \%$ added oil (wt/wt)] levels of fish oil, with high levels of fish oil targeted to deliver $145 \mathrm{mg}$ of docosahexaenoic acid + eicosapentaenoic acid/170 g of yogurt. In a preliminary study, untrained panelists $(\mathrm{n}=$ 31 ), using triangle tests, did not discriminate between low levels of fish and butter oils in unflavored yogurts but could discern yogurt with oxidized fish oil, even at the low level. Trained panelists $(\mathrm{n}=12)$ described lower lime and acid flavor characteristics in CL-flavored yogurts containing 1\% oxidized fish oil compared with yogurts containing low levels of oxidized fish oil and low or high levels of butter and fish oils. Oxidized flavor was higher in CL-flavored yogurts with oxidized fish oil (low and high) and with the high level of fish oil. Consumer ratings ( $\mathrm{n}=100 ; 9$-point hedonic scale; $9=$ "like extremely) of overall acceptability and flavor acceptability were bimodally distributed, with overall means between 4 and 5 ("neither like nor dislike") for CLflavored yogurt with butter or fish oils (high level). The upper $50 \%$ of responses for yogurt with butter or fish oil were 6.51 and 6.31 , respectively, for overall acceptability ("like slightly"), and 7.02 and 6.56, respectively, for flavor acceptability. A large segment of consumers may be interested in incorporating heart-healthy n-3 lipids in their diets through frequent consumption of a savory yogurt enriched with n-3 fatty acids.
\end{abstract}

Key words: yogurt, fish oil, oxidation, sensory

Received October 1, 2011.

Accepted November 22, 2011.

${ }^{1}$ Corresponding author: duncans@vt.edu

\section{INTRODUCTION}

The US Food and Drug Administration has determined that sufficient scientific evidence supports the finding that n-3 FA can help maintain heart health, allowing foods and dietary supplements containing eicosapentaenoic acid (EPA) and docosahexaenoic acid (DHA) to carry a qualified health claim that the product "may be beneficial in reducing coronary heart disease" (FDA, 2004). Increased n-3 FA consumption can help lower blood pressure, reduce blood triglyceride levels, and aid in the secondary prevention of cardiovascular disease (Jacobson, 2006). Most of the US population does not consume the recommended levels of these n-3 FA (200 to $1,428 \mathrm{mg} / \mathrm{d}$; Simopoulos et al., 1999; WHO, 2003; USDA, 2010; AHA, 2011), which are naturally found in fish and fish products, and continues to search for ways to incorporate these healthy fats in their diets. Foods fortified with n-3 FA provide alternatives for people with dietary restrictions or adverse reactions to fish products.

The international popularity of yogurt and the health-promoting properties associated with probiotics, minerals (e.g., calcium), vitamins, and milk proteins establish yogurt as an excellent vehicle for delivery of n-3 FA to consumers. Research investigating the addition of FA to yogurt from fish or algae oil sources (Chee et al., 2005; Kolanowski and Laufenberg, 2006; Kolanowski and Weißbrodt, 2007) and the increasing number of new n-3-enriched dairy products on the market (US and international) exemplify the interest of industry and consumers. Challenges faced when enriching yogurt with n-3 FA include sufficient fortification to help consumers receive the recommended levels needed for the potential health benefits, prevention of oxidative degradation of these highly susceptible n-3 FA-rich lipids, and prevention of off-flavors and odors associated with n-3 FA sources (usually algae or fish oil). Commercially available yogurt products enriched with n-3 FA-rich lipids typically contain low amounts of these lipids per serving (20-60 mg; Rognlien, 2010), thus limiting the risk of off-flavors or odors but requiring consumption of 4 or more servings to achieve the targeted daily intake $(250+\mathrm{mg})$. Based on sensory evaluation of fish oil-enriched (1\% wt/wt) milk and drinking yogurts 
by 9 trained panelists, Nielsen et al. (2009) concluded that yogurt provided a much better base to mask fishy flavors and odors and oxidation than did milk. Fish oil-enriched milk underwent oxidation more quickly than yogurt, possibly during emulsification, due to the higher oxygen content in milk. The authors suggested that the low $\mathrm{pH}$ in yogurt might have contributed to repulsion of metal ions that catalyze oxidation, and proteins that stabilize the matrix may have retarded the oxidative degradation of fish oils.

Fat content and flavoring system influence the perception of fish oil in dairy-based systems. Kolanowski and Weißbrodt (2007) reported that 2 and $3 \mathrm{~g}$ of fish $\mathrm{oil} / \mathrm{kg}$ of yogurt was within the upper tolerable level of fish oil addition in unflavored and strawberry-flavored yogurt, respectively, but no direct indication of EPA or DHA concentration was reported. Other dairy products such as spreadable fresh cheeses (unflavored and garlic), butter (unflavored), or processed cheeses (unflavored, garlic and vanillin flavored), which were fortified with levels up to $60 \mathrm{~g}$ of fish oil $/ \mathrm{kg}$ of product, received overall sensory quality scores $>4.5$ on a 6 -point scale. Increased levels of fat and flavorings help mask fish taste in dairy products fortified with fish oil (Kolanowski and Weißbrodt, 2007). Chee et al. (2005) suggested that fishy flavor in n-3 FA added to strawberry yogurt from an algae source was masked by the strawberry fruit base.

Consumers motivated by health trends may make different choices than other population segments. Healthconscious consumers like drinking yogurts with vastly different characteristics than consumers motivated by price, convenience, mood, or familiarity, as reported by Pohjanheimo and Sandell (2009). Thicker yogurt and more sour and genuine yogurt flavors were perceived as more pleasant by those who were motivated by health. Further, this group was willing to consume yogurts with lower levels of sweetness. Pohjanheimo and Sandell (2009) encouraged the development of yogurts and advertising campaigns that connect product attributes to consumer desires. A recent new product trend in exotic flavors, such as chile-lime, provides innovation opportunities for yogurt products with applications as a food complement or for direct consumption (Anthony, 2009). Strained, or Greek, yogurt products, which are thicker, and savory flavors, such as cucumber, are gaining popularity (Anonymous, 2010). Citrus and spice flavors are popular flavorings for many ethnic foods and commonly used in fish-based dishes, as evidenced in cookbooks and recipe websites, suggesting these flavors may assist in masking or complementing flavor or aroma notes common to n-3 FA-rich lipids sources.

This project investigated the effects of enriching a savory yogurt product with fresh and oxidized fish oils, compared with butter oil, on sensory characteristics and acceptability.

\section{MATERIALS AND METHODS}

\section{Yogurt Manufacture}

Preparation of Milk and Oil Sources. Raw milk obtained from the Virginia Tech dairy farm was heated $\left(60^{\circ} \mathrm{C}\right)$ and separated into skim and cream using a pilot-scale cream separator (Elecrem model 3, 6,400 rpm, Bonanza Industries Inc., Calgary, Canada) in the dairy pilot plant (Food Science and Technology Department, Virginia Tech, Blacksburg). Clarified butter oil was prepared by manufacturing butter from fresh $(<1$ d) cream, and then melting and separating into oil and aqueous phases. The oil phase was collected and used as butter oil for the duration of the study. Oxidized fish oil was prepared by exposing approximately $1 \mathrm{~L}$ of fresh fish oil (DenOmega, Gamle Fredrikstad, Norway) to air and fluorescent light, to induce auto- and photooxidation, at room temperature $\left(22 \pm 3^{\circ} \mathrm{C}\right)$ for $7 \mathrm{~d}$ until a strong oxidized odor was detected. All oils (butter, fish, and oxidized fish) were flushed with nitrogen and stored at $-15^{\circ} \mathrm{C}$ in the dark throughout the study $(<3 \mathrm{mo})$ to protect against any additional oxidation. Peroxide values of fish oils, determined by the titration method (AOAC, 1997; method 965.33) were $0 \mathrm{mEq} /$ $\mathrm{kg}$ for fresh fish oil and $3.9 \mathrm{mEq} / \mathrm{kg}$ for oxidized fish oil. These levels compare with low levels of oxidation reported in the literature, although the oxidized aroma of the oil was quite strong. Antioxidants (mixed tocopherols, lecithin, ascorbyl palmitate, and rosemary extract) were listed for the fish oil by the manufacturer and probably limited the oxidative degradation from light and air exposure.

Yogurt Formulation and Fermentation. Yogurt was formulated using the ingredients and levels listed in Table 1. The targeted yogurt fat content for all products was low fat, with 2 different total fat levels. Yogurt at the low level of oil addition had 1.1 to $1.2 \%$ total fat, and yogurt at the high oil addition level had a total fat content of $1.6 \%$ (Rognlien, 2010). Ingredients were mixed together with an immersion hand blender (Kitchen Aid, St. Joseph, MI), heated $\left(54^{\circ} \mathrm{C}\right)$, and then homogenized in 2 stages $(3.4 / 17.2 \mathrm{MPa})$ using a laboratory homogenizer (model 15MR, APV Gaulin Inc., Everett, MA). The yogurt mix was vat pasteurized at $85^{\circ} \mathrm{C}$ for $30 \mathrm{~min}$ and cooled to $40^{\circ} \mathrm{C}$. Yogurt was fermented with Streptococcus thermophilus and Lactobacillus bulgaricus cultures (Ultra gro UG-55, Cargill, Minneapolis, MN) at $40.9^{\circ} \mathrm{C}$ to a titratable acidity of 0.019 to 0.020 (final $\mathrm{pH}$ of 4.1-4.2). Postfermentation, yogurt was stored at $4^{\circ} \mathrm{C}$ for the duration of testing. All 
Table 1. Formulations (average $\%$, wt/wt) for $n-3$ fortified yogurt ${ }^{1}$ evaluated in 2 different sensory studies

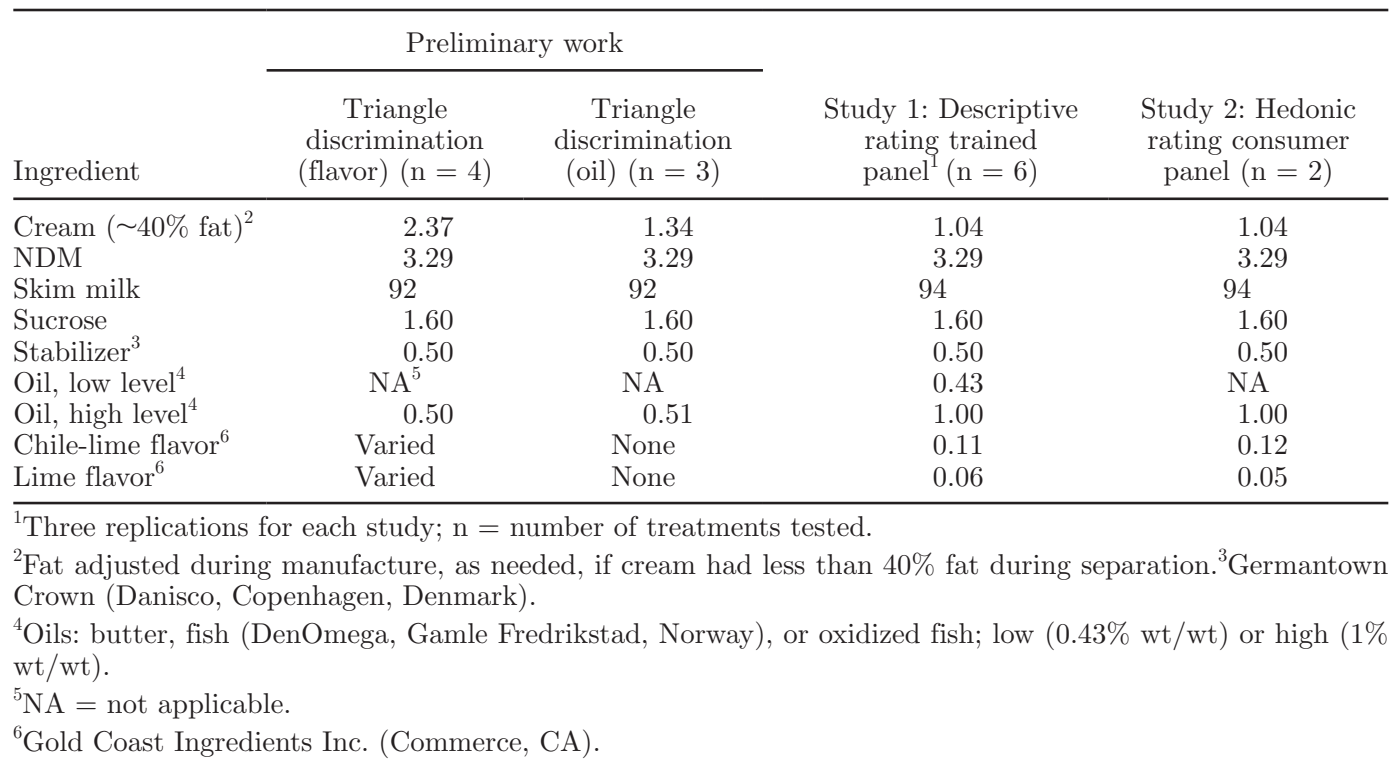

sensory testing was completed within 1 to 2 wk following processing. Three replications of each formulation were prepared over the course of the study.

\section{Yogurt Analysis}

Characterization of yogurt composition was completed on all products based on dairy standard methods (Wehr and Frank, 2004). Physical, compositional, and chemical measurements were completed on all treatments within $4 \mathrm{~d}$ of manufacture.

Lipids were extracted from freeze-dried yogurts (Freezone 18, LabConco, Kansas City, MO) with a modified Soxhlet extraction using methylene chloride (Strugnell, 1991). An internal standard (C23:0 methyl ester) for calculation of percentage fatty acid from the gas chromatograph was added to approximately $25 \mu \mathrm{g}$ of extracted fish or butter oils; oils were then esterified as described by Maxwell and Marmer (1983). To esterify samples, isooctane $(1 \mathrm{~mL})$ was added to oils containing the internal standard along with $200 \mu \mathrm{L}$ of $2 N$ potassium hydroxide in methanol. Samples were vortexed and centrifuged $(300 \times g$ for 10 minutes at $21^{\circ} \mathrm{C}$ ) and the lower layer discarded. Aqueous saturated ammonium acetate $(0.5 \mathrm{~mL})$ was added, the sample was mixed again, centrifuged, and the lower layer discarded; this process was repeated with $0.5 \mathrm{~mL}$ of deionized water. Finally, a small amount of sodium sulfate was added; the mixture sat undisturbed for $5 \mathrm{~min}$, and then was centrifuged and the top layer analyzed by GC. One microliter of sample was injected.

A modified method for fatty acid composition by capillary column gas-liquid chromatography (Maxwell and Marmer, 1983) was used to determine fatty acid methyl ester profiles and calculate levels of DHA and EPA in the final products. A CG-17A gas chromatograph (Shimadzu, Kyoto, Japan) equipped with an SP-2560 [non-bonded poly(bis-cyanopropyl siloxane); Supelco, Sigma-Aldrich, St. Louis, MO] capillary column (100 $\mathrm{m} \times 0.25 \mathrm{~mm} \times 0.2 \mu \mathrm{m})$, split (1:20) injection, helium carrier gas, and a linear flow velocity of $35 \mathrm{~cm} / \mathrm{min}$ was used to separate the fatty acids. An oven program, initial temperature of $130^{\circ} \mathrm{C}$, increased to $240^{\circ}$ at $2^{\circ} \mathrm{C} /$ min, and held for 10 min with a total run time of 65 min, was used with injector and detector port temperatures set to $270^{\circ} \mathrm{C}$. A quadrupole mass spectrometer (QP5050A, Shimadzu) with Gas Chromatography Mass Spectroscopy Real Time Analysis software (version 1.1, Shimadzu), in conjunction with the National Institute of Standards and Technology 2005 Mass Spectral Database, was used to identify chromatographic peaks.

\section{Sensory Analysis}

All sensory studies were approved by the Virginia Tech Institutional Review Board and followed appropriate protocols as described in Meilgaard et al. (2007). All sensory testing took place in the Food Science and Technology Department sensory laboratory at Virginia Tech in individual sensory booths. Information and data were collected using touch computer screens and sensory software (Sensory Information Management System 2000, Version 6, Morristown, NJ). Snacks were used as an incentive for participation in the sensory studies.

A preliminary experiment was conducted to determine if panelists could detect fresh and oxidized fish oils in unflavored yogurt (Table 1). Yogurt samples 
(approximately $28 \mathrm{~g}$ each), divided into portion cups (model P100, Solo Cup Company, Urbana, IL) and sealed with lids, were identified by random 3-digit codes and presented at $4^{\circ} \mathrm{C}$ in a balanced order in a randomized complete block design. Water and unsalted crackers were available during a 1-min rest period between sample sets to refresh the palate. Thirty-one panelists completed 3 sets of triangle tests in 1 session to determine if the addition of fish oil or oxidized fish oil was detectable in unflavored yogurt. Statistical analysis was performed using the significance parameters of $\alpha$ $=0.05, \beta=0.30$, estimate of proportion of discriminators $\left(\mathrm{p}_{\mathrm{d}}\right)=30 \%$ (Meilgaard et al., 2007). Differences $(P<0.05)$ in $0.5 \%$ (wt/wt) addition of oxidized fish oil compared with both butter and fresh fish oil in unflavored yogurt were observed (Table 2). Although not statistically different $(P=0.0589)$, very discriminating individuals may perceive the addition of $0.5 \%$ (wt/wt) fish oil in unflavored yogurt compared with unflavored yogurt with butter oil.

In another preliminary experiment, chile-lime (CL)flavored yogurts, with varied levels of flavoring added, were manufactured with $0.5 \%$ fat added: butter oil (control), fish oil, or oxidized fish oil (Table 1). Flavoring comparisons using triangle tests ( $\mathrm{n}=32$ panelists), as described previously, included (1) unflavored versus $0.09 \%$ CL flavor; (2) $0.09 \%$ CL flavor versus $0.09 \%$ CL $+0.065 \%$ lime flavor; (3) $0.09 \%$ CL flavor versus $0.09 \%$ CL + $0.085 \%$ lime flavor; and (4) $0.11 \%$ CL flavor versus $0.09 \%$ CL+0.085\% lime flavor. Although untrained panelists $(\mathrm{n}=32)$ could significantly $(P<$ 0.05 ) distinguish between CL-flavored (with and without additional lime flavoring) and unflavored yogurt, differences were not found when comparing increases in CL flavoring alone (Table 2), providing guidance as to the levels of CL flavoring in a dairy-based system. Results of the triangle tests for flavor indicated that untrained panelists could distinguish changes at relatively low flavor concentrations in a yogurt base. This information was used to establish flavoring levels used in the product preparation for the descriptive and consumer studies.

A brief survey, including demographic and general interest questions about n-3 FA and flavoring additions to dairy foods and yogurt, was completed by panelists in the 2 preliminary studies. Many participants in the preliminary panel $(50 \%)$ reported that they supplemented their diet with n-3 FA through foods or supplements; $73 \%$ of panelists also indicated they would consume an n-3 FA-fortified dairy product 1 to $3 \mathrm{~d} /$ wk or more often, indicating that consumers are searching for novel and easy ways to incorporate n-3-rich lipids into their diets. Yogurt would provide a good food vehicle for delivering these lipids into the US diet. About half (51\%) of respondents were "likely" or "highly likely" to consume a savory (i.e., full-flavored, not sweet) yogurt product. Fruits (40\%), grains (18\%), and meats (16\%) were identified as the best food companions for the CLflavored yogurt tasted.

Discrimination results were used to identify potential panelists who could discriminate between changes in yogurts with different levels and variations of CL flavoring and types of lipid. Panelists with 4 or more correct responses to the 7 triangle tests on flavorings and oils were invited to participate in training for study 1. A more complete survey was developed, based on preliminary results, for use in the consumer study.

\section{Study 1: Changes in Flavor Profile of CL-Flavored Yogurt with Varied Oil Sources and Levels}

Chile-lime-flavored $(0.11 \% \mathrm{CL}+0.60 \%$ lime flavor $)$ yogurts with 2 lipid levels were manufactured following previously described methods using the formulations shown in Table 1.

Twelve panelists ( 4 males, 8 females) with prior sensory experience in yogurt and oxidation of dairy products were selected to participate in further training, based on performance on the triangle tests (preliminary work) and willingness to participate. Panelists under-

Table 2. Discriminating flavor [chile-lime (CL, \% by weight), lime, none] and oils (butter, fish, oxidized fish) in low-fat yogurt $\left(4^{\circ} \mathrm{C}\right)$ using triangle tests with untrained panelists ${ }^{1}$

\begin{tabular}{|c|c|c|}
\hline Comparison & $P$-value & Significant \\
\hline \multicolumn{3}{|l|}{ Flavor comparison ( $\mathrm{n}=32$ panelists; $0.50 \% \mathrm{wt} / \mathrm{wt}$ butter oil, $1.3 \%$ fat) } \\
\hline Unflavored vs. CL flavor $(0.09 \%)$ & 0.0007 & Yes \\
\hline CL flavor $(0.09 \%)$ vs. CL $(0.09 \%)+$ lime flavor $(0.065 \%)$ & 0.0377 & Yes \\
\hline CL $(0.09 \%)+$ lime flavor $(0.065 \%)$ vs. CL $(0.09 \%)+$ lime flavor $(0.085 \%)$ & 0.0064 & Yes \\
\hline CL $(0.09 \%)+$ lime flavor $(0.085 \%)$ vs. CL flavor $(0.11 \%)$ & 0.2427 & No \\
\hline \multicolumn{3}{|l|}{ Oil comparison $(\mathrm{n}=31$ panelists; $0.51 \% \mathrm{wt} / \mathrm{wt}$ source oil, $1.1 \%$ fat $)$} \\
\hline Butter oil vs. fish oil & 0.0589 & No \\
\hline Fish oil vs. oxidized fish oil & 0.0111 & Yes \\
\hline Butter oil vs. oxidized fish oil & 0.0004 & Yes \\
\hline
\end{tabular}

${ }^{1}$ Statistical parameters for defining sensitivity in triangle tests were $\alpha=0.05, \beta=0.30, \mathrm{p}_{\mathrm{d}}=30 \%$ (Meilgaard et al., 2007), where $\mathrm{p}_{\mathrm{d}}=$ estimate of proportion of discriminators. 
Table 3. Reference standards for training of a descriptive panel for chile-lime flavored yogurt with butter oil, fresh fish oil, and oxidized fish oil

\begin{tabular}{|c|c|c|}
\hline $\begin{array}{l}\text { Sensory } \\
\text { attribute }\end{array}$ & Source & Sample preparation \\
\hline Lime & $\begin{array}{l}\text { Organic Lime Flavor (Gold Coast } \\
\text { Ingredients Inc., Commerce, CA) }\end{array}$ & $\begin{array}{l}\text { Four levels }(0.05-0.12 \%) \text { in } 3 \text { food matrices (filtered water, low-fat milk, plain low-fat } \\
\text { yogurt). Low and high levels in yogurt were standards for anchors on } 15 \text {-cm line scale. }\end{array}$ \\
\hline Heat & $\begin{array}{l}\text { Natural Chile Flavor Concentrate } \\
\text { (Gold Coast Ingredients Inc.) }\end{array}$ & $\begin{array}{l}\text { Four levels }(0.40-0.11 \%) \text { in } 2 \text { matrices (low-fat milk, plain low-fat yogurt). Low } \\
\text { and high levels in yogurt were standards for anchors on } 15-\mathrm{cm} \text { line scale. }\end{array}$ \\
\hline Oxidized & Oxidized canola oil & $\begin{array}{l}\text { Four levels }(0.42-1.02 \%) \text { in } 3 \text { food matrices (fresh vegetable oil, low-fat milk, plain low- } \\
\text { fat yogurt). Low and high levels in yogurt were standards for anchors on } 15 \text {-cm line scale. }\end{array}$ \\
\hline
\end{tabular}

went training for 5 predetermined attributes (lime, sweet, heat, acid, and oxidized) in six 1-h sessions. Reference standards were used to introduce panelists to each attribute of interest (Table 3). The goals of training were (1) to develop terminology related to the product attributes of interest; and (2) to learn the scaling method (Meilgaard et al., 2007), using 4 levels of each attribute in different matrices (water, low-fat milk, and plain low-fat yogurt). Products (approximately 28 $\mathrm{g})$, portioned into 1-oz cups $(\sim 25 \mathrm{~mL})$ and sealed with lids, were identified by 3-digit codes and presented at $4^{\circ} \mathrm{C}$ in a balanced order in a randomized complete block design. Training was validated by testing panelists on 2 separate days with identically prepared samples per session, and then comparing the results (numerical translations measured from $15-\mathrm{cm}$ line scales, with 0 and 15 representing "none" and "extreme," respectively) of individual panelists using a statistical $t$-test. A few panelists required refinement for the oxidized attribute as determined by the validation testing; this was achieved with additional practice.

The trained panel assessed CL-flavored yogurts $(\mathrm{n}=$ 6 treatments) with high and low levels of butter, fish, and oxidized fish oils for 5 attributes (lime, sweet, heat, acid, oxidized) using 15-cm unstructured line scales, following the same protocols established during training. Statistical analysis on the 3 replications was completed with JMP Statistical Software (SAS Institute Inc., Cary, NC). Results from all replications of the line scales were tabulated and an ANOVA table with Tukey's honestly significant difference (HSD) compared for the 6 formulations for each attribute. For the trained sensory panel, a 2-way ANOVA was conducted using the following model:

$$
Y_{i j}=\mu+L_{i}+S_{j}+L S_{i j}+\varepsilon_{i j}
$$

where $Y_{i j}$ is the $i j$ th observation; $\mu$ is the general mean; $L_{i}$ (oil level; low or high) and $S_{j}$ (oil source; butter oil, fish oil, or oxidized fish oil) are the main effects; $L S_{i j}$ is their interaction; and $\varepsilon_{i j}$ is the random error.

\section{Study 2: Consumer Perception of CL-Flavored Yogurt as a Dietary Source of n-3 Lipids}

Two formulations of CL-flavored (0.12\% CL + 0.05\% lime flavor) yogurts (endpoint $\mathrm{pH}$ of 4.3 ) were manufactured, as described previously (Table 1), for determining overall and flavor acceptance of the products using a consumer sensory panel. Formulations consisted of $1 \%$ (wt/wt) clarified butter oil or fresh fish oil.

Demographics and responses to questions pertaining to product use, general awareness, and interest in dietary sources of dairy, fish, and n-3 food sources were collected from 186 students, faculty, staff, and local community members in and around Virginia Tech using an electronically delivered survey (www.survey. vt.edu). One hundred of these subjects were selected to participate in the consumer sensory study based on willingness to participate, having no allergies or health conditions prohibiting participation, and being regular consumers of yogurt (consume 1 to 3 times per month or more). This subgroup of consumers was $66 \%$ female, mostly (66\%) aged 18 to $25 \mathrm{yr}$, and mostly (84\%) Caucasian/white. Panelists ranged from 18 to $>70 \mathrm{yr}$ of age and had diverse backgrounds; most had limited experience participating in sensory panels.

The consumer sensory panel $(\mathrm{n}=100)$ determined overall acceptance and flavor acceptance of CL flavoring in yogurt using a 9-point hedonic scale $(1=$ "dislike extremely," 9 = "like extremely"). Yogurt (28 g) was portioned into 1-oz cups and sealed with lids, identified by 3-digit codes representing each product, and presented at $4^{\circ} \mathrm{C}$ in a balanced order. Panelists were given 2 sets of CL-flavored yogurt samples; each set consisted of one butter oil-enriched and one fish oil-enriched sample. The first set was used for evaluation of overall acceptance and flavor acceptance was evaluated in the second set.

Data analysis was completed using Excel (Microsoft Corp., Redmond, WA) to tabulate results of surveys and questions, and then calculate and report percentages. Hedonic rating scores were averaged and com- 
Table 4. Mean concentrations of eicosapentaenoic acid (EPA) and docosahexaenoic acid (DHA) in source oils (butter, fish, oxidized fish) and chile-lime flavored oil-supplemented yogurt products at 2 fat levels ${ }^{1,2}$

\begin{tabular}{|c|c|c|c|c|c|}
\hline Item & $\begin{array}{c}\text { EPA } \\
(\mathrm{mg} / \mathrm{g} \text { of oil) }\end{array}$ & $\begin{array}{c}\text { DHA } \\
(\mathrm{mg} / \mathrm{g} \text { of oil })\end{array}$ & $\begin{array}{c}\mathrm{EPA}+\mathrm{DHA} \\
(\mathrm{mg} / \mathrm{g} \text { of oil })\end{array}$ & $\begin{array}{c}\mathrm{EPA}+\underset{(\text { wt } \%)}{\mathrm{DHA}} \\
\end{array}$ & $\begin{array}{c}\mathrm{DHA}+\mathrm{EPA} \\
\text { delivered } \\
\text { (mg/170-g } \\
\text { serving) }\end{array}$ \\
\hline \multicolumn{6}{|l|}{ Source oil } \\
\hline Fish oil ${ }^{3}$ & $99.55 \pm 6.25^{\mathrm{a}}$ & $99.74 \pm 4.88^{\mathrm{a}}$ & $199.3^{\mathrm{a}}$ & $23.29^{\mathrm{a}}$ & NA \\
\hline Oxidized fish oil & $105.5 \pm 7.53^{\mathrm{a}}$ & $105.6 \pm 6.60^{\mathrm{a}}$ & $211.1^{\mathrm{a}}$ & $23.35^{\mathrm{a}}$ & NA \\
\hline Butter oil & $\mathrm{NA}^{4}$ & NA & NA & & \\
\hline \multicolumn{6}{|l|}{ Yogurt } \\
\hline Butter oil-low 5 & NA & NA & NA & & \\
\hline Butter oil-high $^{5}$ & NA & NA & NA & & \\
\hline Fish oil-low & $38.15 \pm 2.95^{\mathrm{c}}$ & $37.32 \pm 2.66^{\mathrm{d}}$ & $75.48^{\mathrm{d}}$ & $10.58^{\mathrm{d}}$ & 150 \\
\hline Fish oil-high & $65.92 \pm 0.87^{\mathrm{b}}$ & $65.26 \pm 0.54^{\mathrm{b}}$ & $131.2^{\mathrm{b}}$ & $16.99^{\mathrm{b}}$ & 357 \\
\hline Oxidized fish oil-low & $50.68 \pm 2.61^{\mathrm{c}}$ & $50.17 \pm 2.47^{\mathrm{c}}$ & $100.9^{c}$ & $13.77^{\mathrm{c}}$ & 200 \\
\hline Oxidized fish oil-high & $69.18 \pm 4.01^{\mathrm{b}}$ & $68.67 \pm 3.77^{\mathrm{b}}$ & $137.9^{\mathrm{b}}$ & $17.54^{\mathrm{b}}$ & 375 \\
\hline \multicolumn{6}{|c|}{$\overline{\mathrm{a}-\mathrm{d}}$ Means with different superscripts within columns are significantly different $(P<0.05)$. } \\
\hline \multicolumn{6}{|c|}{${ }^{1}$ Mean values of triplicate analyses $\pm \mathrm{SD}$} \\
\hline \multicolumn{6}{|c|}{${ }^{2} \mathrm{EPA}$ and DHA were calculated based on tricosanoic acid internal standard. } \\
\hline \multicolumn{6}{|c|}{${ }^{3}$ DenOmega (Gamle Fredrikstad, Norway). } \\
\hline \multicolumn{6}{|c|}{${ }^{4} \mathrm{NA}=$ not available. } \\
\hline${ }^{5} \mathrm{Low}=0.43 \% \mathrm{wt} / \mathrm{wt}$ & & & & & \\
\hline
\end{tabular}

pared using a statistical t-test. Statistical evaluation used JMP (SAS Institute Inc.) models with a preset $\alpha$ of 0.05 for determining significant differences.

\section{RESULTS AND DISCUSSION}

The addition of fish oil to yogurt as a source of n-3 FA is of concern because of potential "fishy" flavor notes from the source oil, yet our goal was to add a sufficient level of oil to provide a significant contribution of n-3 FA into the daily diet while minimizing fishy notes. In preliminary testing, panelists $(\mathrm{n}=31)$ could not differentiate between yogurt with butter oil $(0.5 \% \mathrm{wt} / \mathrm{wt})$ and fish oil $(0.5 \% \mathrm{wt} / \mathrm{wt})$ in unflavored yogurts (Table 2 ). This level of fortification was calculated to supply $187 \mathrm{mg}$ of DHA + EPA per 170-g serving of yogurt, based on the fish oil source used in this study. Carlson et al. (2010) reported that deodorized fish oil blended with butter oil (25\%:75\%, respectively) was not detectable, based on triangle tests $(\mathrm{n}=30)$ in a $0.4 \%$ fat unflavored yogurt, whereas flax oil was noticeable even at 20:80 (flax:butter oil) blend (Carlson et al., 2010).
They also reported the sensory threshold for oxidized fish oil in unflavored yogurt was $>0.2 \%$ (wt/wt).

\section{Study 1: Effects of Oxidized and Fresh Fish Oil on Sensory Characteristics}

Yogurts produced for the descriptive study were similar in gross composition, differing only between low and high fat composition, as intended (data not shown). Significant differences $(P<0.05)$ in EPA and DHA concentrations between low and high levels of oil fortification were expected and observed. The proportion of fish oil and butter oil in the different products influenced fatty acid composition, as expected (data not shown). Calculations from analysis of fatty acid methyl esters showed that fish oil and oxidized fish oil yogurts were fortified with greater than the recommended daily values per serving of yogurt, even at low levels of fish oil addition (Table 4).

Significant differences in oxidized, lime, and acid sensory attributes were found in yogurt with different levels and different types of oil (Table 5). Lime and acid

Table 5. Effects ( $P$-values) of oil source (butter, fish, or oxidized fish) and oil level $(0.43$ or $1 \%)$ on flavor attributes of chile-lime flavored yogurt products evaluated by a trained panel $(\mathrm{n}=12 ; 3$ replications)

\begin{tabular}{lcccc}
\hline Attribute & $\begin{array}{c}\text { All } \\
\text { formulations }\end{array}$ & $\begin{array}{c}\text { Oil } \\
\text { source }\end{array}$ & $\begin{array}{c}\text { Oil } \\
\text { level }\end{array}$ & $\begin{array}{c}\text { Interaction } \\
(\text { source } \times \text { level) }\end{array}$ \\
\hline Acid & 0.0220 & 0.0113 & 0.8671 & 0.1194 \\
Heat & 0.2902 & 0.6676 & 0.1396 & 0.2037 \\
Lime & 0.0017 & 0.0310 & 0.1264 & 0.0056 \\
Oxidized & $<0.0001$ & $<0.0001$ & 0.0003 & 0.0193 \\
Sweetness & 0.4840 & 0.5443 & 0.4337 & 0.2681 \\
\hline
\end{tabular}


flavors were perceived as significantly $(P<0.05)$ lower in yogurt with a high level of oxidized fish oil compared with other formulations; this could be attributed to the oil source and not the oil levels (Table 5). The trained sensory panel $(\mathrm{n}=12)$ found no significant differences in flavor attribute intensity between levels of butter oil, suggesting that a small difference in milkfat $(\leq 1 \% \mathrm{wt} /$ wt) does not affect flavoring systems in yogurt.

Oxidized oils typically contain higher levels of volatile aldehydes, ketones, and other low molecular weight compounds that may mask or interfere with the perception of lime flavor. Oxidized flavor characteristics were higher, as anticipated, in the high-oxidized fish oil yogurt formulation and significantly different $(P<$ $0.05)$ from yogurts with low levels of oxidized fish oil and high levels of fresh fish oil formulations (Figure 1). Yogurts with low amounts of fresh fish oil and both butter oil formulations had significantly $(P<0.05)$ lower oxidized flavor than the other formulations. A high level (1\%) of fresh fish oil fortification in a CL-flavored yogurt product could be distinguished from a low level $(0.43 \%)$ of fish oil by a trained sensory panel, perhaps because the "fishy" character of the oil became evident and was captured in the "oxidation" characteristic. At low levels $(0.43 \%)$ of fish oil in a CL-flavored yogurt product, the perception of oxidized flavor could not be distinguished from formulations made using butter oil at 0.43 or $1 \%$.

\section{Study 2: Consumer Acceptance of Chile-Lime n-3 FA-Enriched Yogurt}

The tested population was representative of a nutritionally motivated consumer population, based on a preliminary screening survey. Almost half of the respondents (47\%) reported having general food and nutrition knowledge, such as a high school or college level introductory food and nutrition class, and only $12 \%$ reported having very limited knowledge. When asked about dairy and n-3 FA health benefits, $87 \%$ reported they were generally or very aware of the potential health benefits associated with regular consumption of milk or dairy products, and $64 \%$ were generally or very aware of the benefits of the consumption of n-3 FA. Most respondents (65\%) reported that they attempted to supplement the levels of n-3 FA in their diet naturally, with fortified foods or supplements, in contrast to $35 \%$ that claimed they did not attempt to increase the n-3 FA intake in their diets. Additional survey questions, completed after the yogurt samples were tasted, indicated that $38 \%$ of the panelists were "unlikely" or "highly unlikely" to consume our CL-flavored yogurt on a regular basis, whereas $39 \%$ were "likely" or "highly likely" to consume it on a regular basis; the remaining respondents were "unsure." The most frequently suggested food complements for the CL-flavored yogurt sampled were fruit $(35 \%)$ and grain $(28 \%)$, given

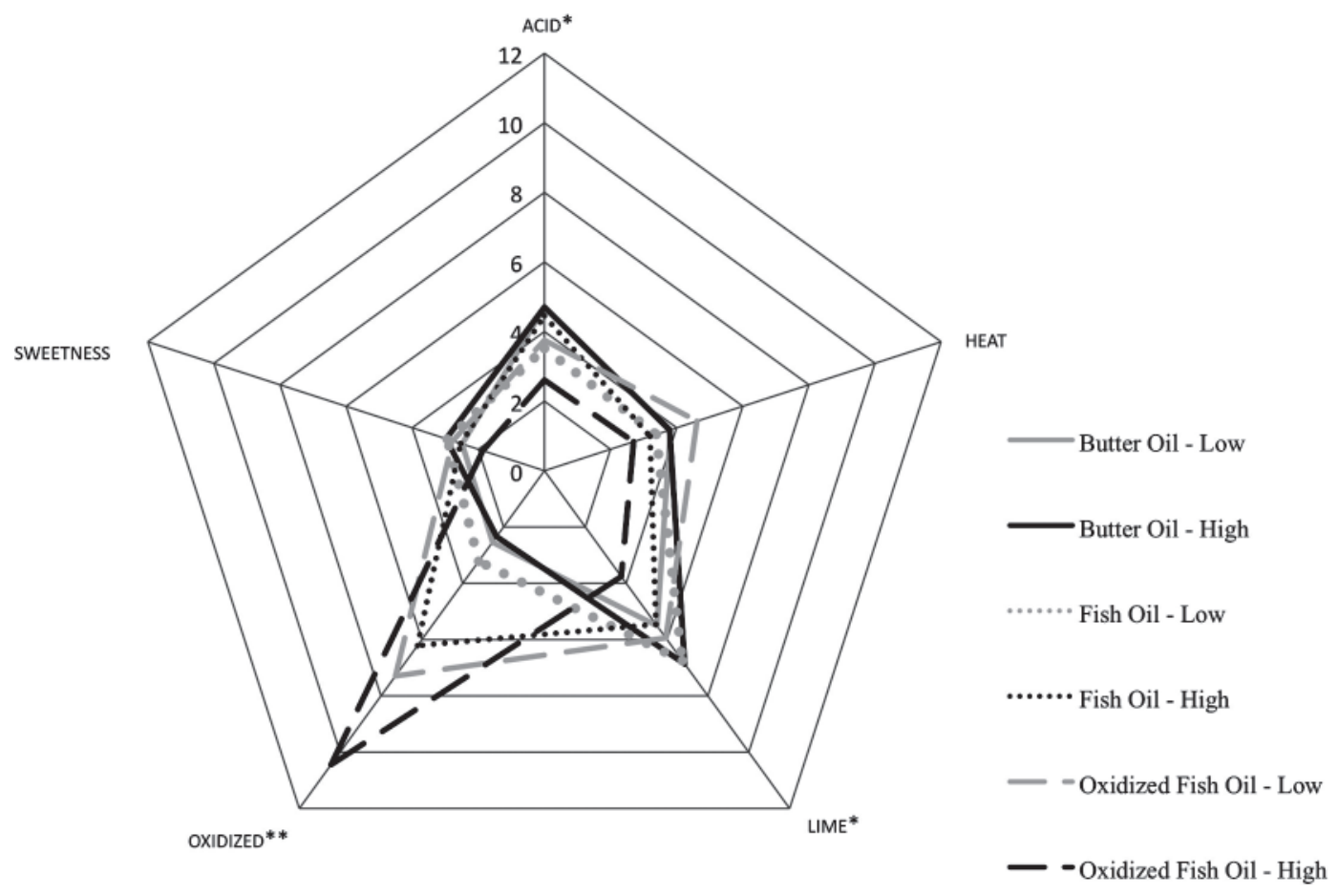

Figure 1. Mean levels of attributes in chile-lime flavored yogurt products by formulation (various oil sources at 0.43 or $1 \%$ ) as determined by a trained sensory panel $(\mathrm{n}=12)$ using a 15 -cm line scale $\left(0=\right.$ none; $15=$ extreme); $\mathrm{n}=3$ replications. ${ }^{*} P<0.05 ; * * P<0.01$. 
choices of nothing (i.e., eat it alone), beverage, meat, fruit, vegetable, grain, and other.

Both overall acceptability and flavor acceptability scores for the CL-flavored yogurt with butter oil and fish oil were bimodally distributed, with means of 4.85 and 4.68, respectively $(P<0.05$; Figure 2$)$. The top $50 \%$ of participant responses were 5 (neither like nor dislike) or higher, and mean values for overall acceptability were 6.51 and 6.31 for CL-flavored yogurt with butter and fish oil, respectively. Flavor acceptability scores were 7.02 and 6.51 , respectively. The low overall acceptability of the products by the remaining $50 \%$ of the population may be attributed primarily to unfamiliarity with or lack of acceptance of CL flavors or with the lack of sweetness in the product. Consumers were not made aware of the flavor system or lack of sweetener in the yogurt to avoid a preconceived bias against savory flavor applications or fear of new foods (food neophobia); panelists may have been surprised by the unanticipated spicy or slight burning sensation of the CL flavoring and the lack of sweetness in the yogurt. Fruit flavors, especially strawberry, are very well accepted in yogurt, whereas consumers are less familiar with savory flavors in yogurt. Fish oil in the yogurt did decrease the flavor
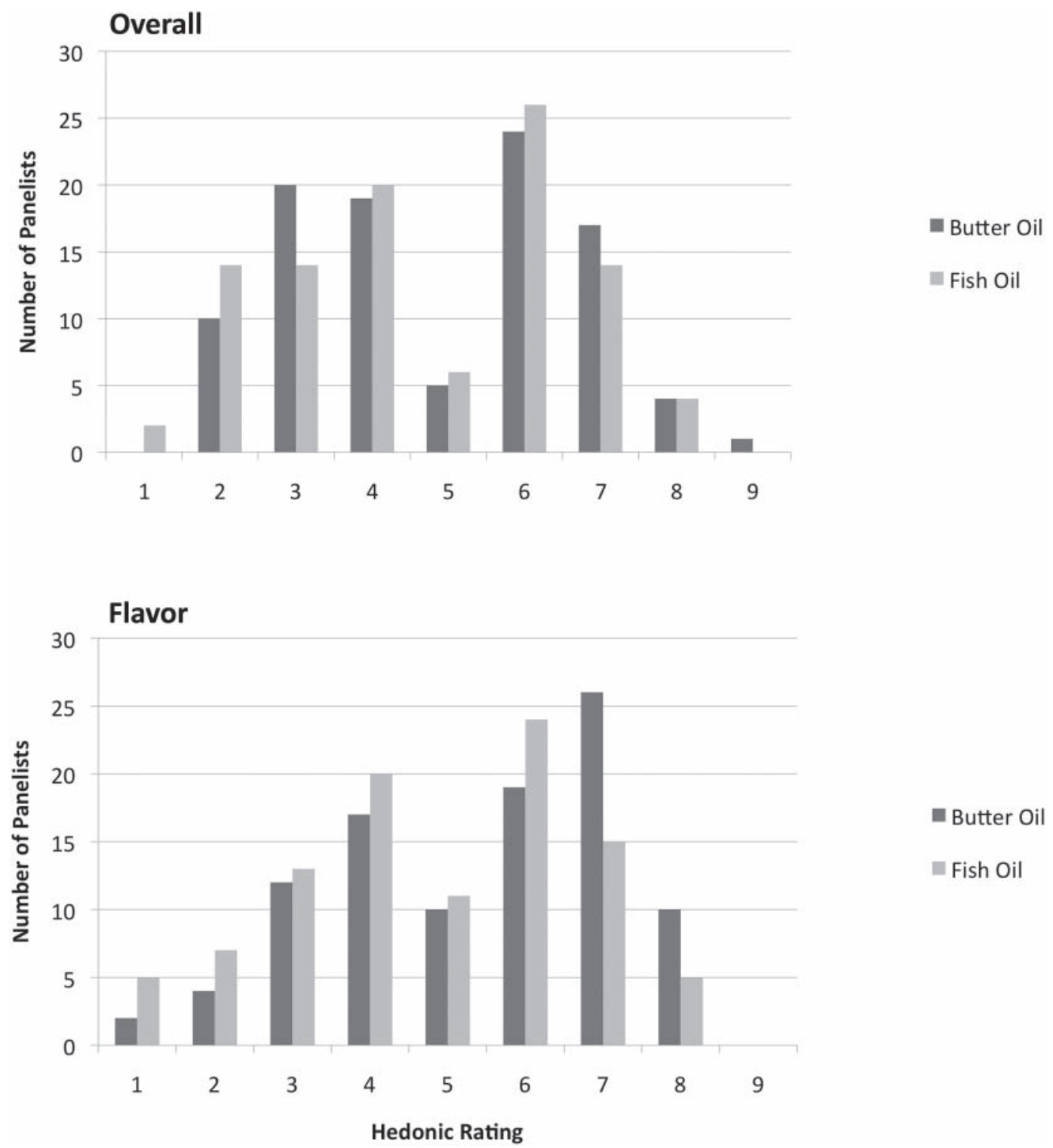

Figure 2. Bimodal distribution of hedonic ratings (9-point scale, $1=$ "dislike extremely," 5 = "neither like nor dislike," $9=$ "like extremely"; $\mathrm{n}=100)$ for overall and flavor acceptability of chile-lime flavored yogurt ( $1.6 \%$ total fat) made with butter oil (overall acceptability mean $=$ 4.85 ; flavor acceptability mean $=5.40$ ) and fish oil (overall $=4.68$; flavor $=4.82$ ). Overall acceptability means for upper $50 \%$ are 6.51 and 6.31 for butter oil- and fish oil-enriched yogurts, respectively. Flavor acceptability means for upper $50 \%$ are 7.02 and 6.51 , respectively. 
acceptability of the product $(P=0.0017)$, based on the mean flavor acceptability scores (butter oil-based yogurt: 5.40; fish oil-based yogurt: 4.82).

Comments from the consumer panel also helped explain the bimodal distribution. The chile flavor and aftertaste were unappealing $(\mathrm{n}=27)$ and the yogurt was too bitter or sour $(\mathrm{n}=51)$ for some. However, the texture $(\mathrm{n}=41)$ and level of sweetness $(\mathrm{n}=12)$ were frequently noted and seemed to be liked by some. The yogurt texture of the pilot-scale product was slightly grainy, possibly because of the low $\mathrm{pH}$ (4.1-4.2), which may have affected overall acceptability. A spicy burning sensation may be surprising, and possibly unpleasant, if a sweet fruit flavor was expected in yogurt, and might be seen as a defect. The burning sensation associated with chile peppers is not universally accepted. Panelists who responded with high hedonic ratings often noted the aroma and refreshing spicy or citrus flavors and some noted the heat sensation on the palate.

These studies suggest that fortification of a savory yogurt with $1 \%$ fish oil could be acceptable to a portion of the general population and have a potential market among health- and nutrition-conscious consumers. Oxidized fish oil added to yogurts, even at low levels of oxidation, was detectable by both trained and untrained panelists. This information is beneficial to manufacturers interested in fish oil fortification of yogurt because consumers may be able to detect products that have oxidized during processing or storage. Consuming oxidized lipids could be a safety hazard because they do not provide benefit to the body, and consumption can be toxic to animals (Kolanowski and Laufenberg, 2006; Venugopal, 2009). However, fish oil-enriched yogurt is highly stable to oxidation, possibly because of the antioxidant activity of peptides released during fermentation (Farvin et al., 2010).

\section{CONCLUSIONS}

Delivering sufficient heart-healthy n-3 FA to achieve the suggested daily intake (145 mg of EPA + DHA) may be accomplished in a single serving (170 g) of savory-flavored yogurt, providing an alternative and easily incorporated dietary source for these valuable fatty acids. Innovation of unsweetened, savory flavoring in combination with the powerful health functionality of n-3 FA and dairy components is of interest to a large segment of the health- or nutrition-aware population. A potential market exists for this population.

\section{REFERENCES}

AHA (American Heart Association). 2011. Fish 101. Accessed Jan. 24, 2012. http://www.heart.org/HEARTORG/GettingHealthy/NutritionCenter/Fish-101_UCM_305986_Article.jsp\#.Tx-DzSPxh7w.

Anonymous. 2010. Sweet, savory Greek yogurt flavors. Virgo Publishing. Accessed Jan. 24, 2012. http://www.foodproductdesign.com/ news/2010/07/sweet-savory-greek-yogurt-flavors.aspx.

Anthony, M. 2009. Flavor and ingredient trends for 2009. Accessed Mar. 10, 2011. http://www.foodprocessing.com/articles/2009/flavortrends.html.

AOAC. 1997. Official Methods of Analysis. 16th ed. AOAC International, Gaithersburg, MD.

Carlson, S., M. Rognlien, Q. Li, and S. Duncan. 2010. Change in sensory characteristics of yogurt due to addition of healthy oils. Abstract 154-01, page 158 in Book of Abstracts: 2010 IFT Annual Meeting Technical Program. Institute of Food Technologists, Chicago, IL.

Chee, C. P., J. J. Gallaher, D. Djordjevic, H. Faraji, D. J. McClements, E. A. Decker, R. Hollender, D. G. Peterson, R. F. Roberts, and J. N. Coupland. 2005. Chemical and sensory analysis of strawberry flavoured yogurt supplemented with an algae oil emulsion. J. Dairy Res. 72:311-316.

Farvin, K. H., C. P. Baron, N. S. Nielsen, and C. Jacobsen. 2010. Antioxidant activity of yoghurt peptides: Part 1. In vitro assays and evaluation in $\omega-3$ enriched milk. Food Chem. 123:1081-1089.

FDA (Food and Drug Administration). 2004. FDA Announces Qualified Health Claims for Omega-3 Fatty Acids. FDA, Washington, DC.

Jacobson, T. A. 2006. Secondary prevention of coronary artery disease with omega-3 fatty acids. Am. J. Cardiol. 98:61i-70i.

Kolanowski, W., and G. Laufenberg. 2006. Enrichment of food products with polyunsaturated fatty acids by fish oil addition. Eur. Food Res. Technol. 222:472-477.

Kolanowski, W., and J. Weißbrodt. 2007. Sensory quality of dairy products fortified with fish oil. Int. Dairy J. 17:1248-1253.

Maxwell, R. J., and W. N. Marmer. 1983. Systematic protocol for the accumulation of fatty acid data from multiple tissue samples: Tissue handling, lipid extraction and class separation, and capillary gas chromatographic analysis. Lipids 18:453-459.

Meilgaard, M. C., G. V. Civille, and B. T. Carr. 2007. Sensory Evaluation Techniques. 4th ed. CRC Press, Boca Raton, FL.

Nielsen, N. S., A. Klein, and C. Jacobsen. 2009. Effect of ingredients on oxidative stability of fish oil-enriched drinking yoghurt. Eur. J. Lipid Sci. Technol. 111:337-345.

Pohjanheimo, T., and M. Sandell. 2009. Explaining the liking for drinking yoghurt: The role of sensory quality, food choice motives, health concern and product information. Int. Dairy J. 19:459-466.

Rognlien, M. 2010. Yogurt as a vehicle for omega-3 fatty acid enrichment. MS Thesis. Virginia Polytechnic Institute and State University, Blacksburg.

Simopoulos, A. P., A. Leaf, and J. N. Salem. 1999. Essentiality of and recommended dietary intakes for omega- 6 and omega- 3 fatty acids. Ann. Nutr. Metab. 43:127-130.

Strugnell, C. J. 1991. Estimation of fat in 'low fat' dairy products. Lab. Pract. 40:53-54

USDA. 2010. Dietary Guidelines for Americans. 7th ed. US Department of Agriculture and US Department of Health and Human Services, Washington, DC.

Venugopal, V. 2009. Marine Products for Healthcare: Functional and Bioactive Nutraceutical Compounds from the Ocean. CRC Press, Boca Raton, FL.

Wehr, H. M., and J. F. Frank. 2004. Standard Methods for the Examination of Dairy Products. 17th ed. American Public Health Association, Washington, DC.

WHO (World Health Organization). 2003. Diet, nutrition and the prevention of chronic diseases. Pages 99-100 in Population Nutrient intake goals for preventing diet-related chronic diseases. WHO, Geneva, Switzerland. 